\title{
Improved prediction equations for estimating height in adults from ethnically diverse backgrounds
}

Authors: Angela M. Madden ${ }^{1}$, Alla Mashanova ${ }^{1}$, Farzad Amirabdollahian², Sandeep Ghuman', Munibah Makda², Avril Collinson ${ }^{3}$, Frances Dean ${ }^{3}$, Malgorzata Hirsz ${ }^{5}$, Susan Lennie ${ }^{4}$, Maria J. Maynard ${ }^{5}$, Brian Power ${ }^{6}$.

Work undertaken at the School of Life and Medical Sciences, University of Hertfordshire, Hatfield AL10 9AB and at five other UK universities.

Present addresses:

${ }^{1}$ School of Life and Medical Sciences, University of Hertfordshire, Hatfield AL10 9AB, UK

${ }^{2}$ School of Health Sciences, Liverpool Hope University, Liverpool L16 9JD, UK ${ }^{3}$ School of Health Professions, University of Plymouth, Plymouth PL6 8BH, UK ${ }^{4}$ School of Health Sciences, Robert Gordon University, Aberdeen AB10 7QG, UK ${ }^{5}$ School of Clinical and Applied Sciences, Leeds Beckett University, Leeds LS1 3HE, UK

${ }^{6}$ Institute for Liver and Digestive Health, University College London, London NW3 2PF, UK

Key words: Nutritional assessment, anthropometry, estimated height, ulna length, prediction equations

Corresponding author: Dr Angela Madden, School of Life and Medical Sciences, University of Hertfordshire, Hatfield AL10 9AB; telephone 01707 281385; email a.madden@herts.ac.uk 


\section{Abstract}

Background and aims: When body height cannot be measured, it can be predicted from ulna length (UL). However, commonly used published prediction equations may not provide useful estimates in adults from all ethnicities. This study aimed to evaluate the relationship between UL and height in adults from diverse ethnic groups and to consider whether this can be used to provide useful prediction equations for height in practice.

Methods: Standing height and UL were measured in 542 adults at seven UK locations. Ethnicity was self-defined using UK Census 2011 categories. Data were modelled to give two groups of height prediction equations based on UL, sex and ethnicity and these were tested against an independent dataset $(n=180)$.

Results: UL and height were significantly associated overall and in all groups except one with few participants $(P=0.059)$. The new equations yielded predicted height $\left(H_{p}\right)$ that was closer to measured height in the Asian and Black subgroups of the independent population than the Malnutrition Universal Screening Tool (MUST) equations. For Asian men, $\left(\mathrm{H}_{\mathrm{p}}(\mathrm{cm})=3.26 \mathrm{UL}(\mathrm{cm})+83.58\right)$, mean difference from measured (95\% confidence intervals) was $-0.6(-2.4,+1.2)$; Asian women, $\left(\mathrm{H}_{p}=3.26\right.$ $U L+77.62)$, mean difference $+0.5(-1.4,2.4) \mathrm{cm}$. For Black men, $\mathrm{H}_{p}=3.14 \mathrm{UL}+$ 85.80, -0.4 (-2.4, 1.7); Black women, $\mathrm{H}_{p}=3.14 \mathrm{UL}+79.55,-0.8(-2.8,1.2)$. These differences were not statistically significant while predictions from MUST equations were significantly different from measured height.

Conclusions: The new prediction equations provide an alternative for estimating height in adults from Asian and Black groups and give mean predicted values that are closer to measured height than MUST equations.

Six key words: Anthropometry; height; ulna; prediction equations; ethnicity; adults. 


\section{Introduction}

Measures of height are used, together with body weight, in clinical nutrition to assess risk of obesity and under nutrition ${ }^{1}$, to estimate basal metabolic rate ${ }^{2}$ and to determine drug dose ${ }^{3}$. In some individuals, measurement of height may be difficult to obtain and / or of questionable accuracy ${ }^{4,5}$ so alternative methods for estimating height are required. Published studies have explored the prediction of height from a range of methods ${ }^{6}$ including knee height ${ }^{7-9}$, arm span $^{10-13}$, demi-span ${ }^{14,15}$, ulna length ${ }^{1,16}$ and hand length ${ }^{17}$. Ulna length is considered to be the most practical method for use in clinical practice which requires minimum undressing, little effort from the person being measured and no complicated equipment ${ }^{18}$. It is recognised that anthropometric measurements, including height, vary between populations ${ }^{11,19-24}$. These differences relate not only to absolute anthropometric measurements, but also to the relationship between variables, for example, arm span is approximately equal to height in White adults but greater than height in Black Africans and Asians ${ }^{19,22}$. Similarly, published equations ${ }^{1}$ describing the relationship between ulna length and height allow useful prediction of height in Black and White adults but their applicability in Asians, particularly women, has been questioned ${ }^{25}$. The aims of this multicentred study were (1) to evaluate the relationship between ulna length and height in adults from a series of diverse ethnic groups and (2) to consider whether ulna measurements can be used to provide useful predictions of height by proposing new prediction equations and testing them using an independent historic dataset. 


\section{Materials and methods}

\section{Participants}

Researchers from six universities collaborated to recruit seven groups of predominantly non-White participants living in the community (Table 1). Inclusion criteria were age $\geq 21$ years and able to stand un-aided for height measurement and to provide informed consent. Participants provided their age, sex and defined their ethnic category and subgroup using the Office for National Statistics UK Census 2011 categories $^{26}$ (Table 2). An anonymised historic dataset ${ }^{25}$ was used for statistical comparison; this was randomly selected from 194 adults aged 21-62 years who provided their self-identified ethnic group using the England and Wales census categories in use at that time ${ }^{27}$.

\section{Standardized measurement procedures}

Participants' height and ulna length were measured by one of ten researchers as described below following the same procedures at all study sites ${ }^{1,25,28}$. Any concern about the validity of a measure was recorded on the data collection sheet and values were subsequently excluded from data analysis. Before participants were measured, each researcher checked their adherence to the measurement procedures by demonstrating these to their site supervisor. They then measured height and left and right ulna length in five adults five times in order to achieve repeat measurements that varied by $<0.5 \mathrm{~cm}$ for height and $<0.3 \mathrm{~cm}$ for ulna length.

Height: Stadiometers (Table 1) were placed on a firm, level surface using either stabilizers positioned against a wall to ensure rigidity or a spirit level. Participants removed shoes and hats and other head-coverings unless these were deemed not to influence the measurement. Hairstyles that would affect height 
measurement were adjusted with permission so that an accurate result was obtained; where this was not possible, data were excluded. Participants stood on the platform of the stadiometer facing forward with shoulders relaxed, arms hanging freely by the sides, legs straight and close together with the upper back, buttocks and heels in contact with the upright section of the stadiometer. Their head was positioned in the Frankfort horizontal plane (Figure 1) so that their lower eye socket was horizontally level with the top of their ear canal. The stadiometer head plate was then lowered to make contact with the top of the head. Three measurements were made and recorded to $0.1 \mathrm{~cm}$.

Ulna length: Participants wearing wristbands, tight jewellery, bracelets or watches that could make the reading inaccurate, were asked to remove them or change their position. Then they bent their left arm at the elbow and placed it across their chest with the fingers pointing to the opposite shoulder (Figure 2). The distance between the point of the elbow (olecranon process) and the midpoint of the prominent bone of the external wrist (styloid process) was then measured three times and values recorded to $0.1 \mathrm{~cm}$. The procedure was then repeated on the right arm.

The same procedures had been used to collect the historic dataset.

\section{Equipment and documentation}

Height was measured using either a Seca 213 portable stadiometer or Leicester height measure (Table 1). The same model was used for all measurements at each site and checked for correct assembly before use. 
Ulna length was measured using a non-stretch anthropometric tape. The same model of tape was used for all measurements at each site but five different makes were used across the seven sites (Table 1).

A standardised two-part data collection sheet was used at all sites. Participants completed the first part on demography with assistance from the researcher if required. The researcher recorded height and ulna length on the second part. A standardised data spreadsheet (Excel, Microsoft) was used at all sites and data from each participant's data collection sheet were entered twice to facilitate electronic checking. The spreadsheets from all sites were checked by the lead author and discrepancies checked back against the original data collection sheets. Data with queries that could not be verified were excluded.

Data analysis

Left and right ulna length were compared using a paired t-test and the right ulna was found to be significantly longer than the left (mean difference $0.05 \mathrm{~cm}, 95 \%$ confidence intervals $0.002,0.100 ; t=2.0465, d f=541, p=0.041)$. Therefore, although this difference was not clinically relevant, the mean values from both right and left ulnas were used for the analysis. Two ethnic groups had too few participants and were excluded from the analysis (Mixed / multiple ethnic groups [Census 2011 subgroups 5-8; 14 participants] and Other ethnic groups [Census 2011 subgroups 17-18; 8 participants], Table 2). For the remaining three groups (White; Asian / Asian British; Black / African / Caribbean / Black British), the effect of ethnicity on the relationship between ulna and height within the groups was checked prior to the main analysis. 
Analysis of covariance was used to explore whether the relationship between height and ulna length was affected by ethnicity and sex starting with the full model including all ethnic subgroups, both sexes and all possible interactions. When interactions were not significant the number of ethnic subgroups was reduced in a step-by-step manner until the reduced model was significantly worse in describing the data than the best model so far ${ }^{29}$. The analysis was undertaken using $R^{30}$. At the first stage, R's 'step()' function was used to obtain the best model which, in most cases, removed the interactions from the models. Then the least different ethnic groups were combined in a step-by-step manner, and ANOVA procedure was used to test whether the model with combined groups was significantly worse than the model with all groups. For the final model, normality of the residuals was checked using the Shapiro-Wilk test.

\section{Historic dataset}

Data from 180 participants in the independent historic dataset were selected using an online random number generator to provide six groups of men and women from Asian, Black and White participants each comprising $n=30$; data were not available to allow further categorisation into Census 2011 subgroups. The equations derived above were then applied to data from relevant ethnic groups in the historic dataset to

give predicted values for height. The published equations of Elia ${ }^{1}$ for adults aged $<65$ years were also used to predict height $(\mathrm{men}$, height $(\mathrm{cm})=3.60$ ulna length $(\mathrm{cm})+$ 79.2; women, height $(\mathrm{cm})=2.77$ ulna length $(\mathrm{cm})+95.6)$. After confirming all data were normally distributed, comparisons were made between measured and predicted height using paired t tests. 
Ethics

Ethical approval for the study was obtained at the lead site from the University of Hertfordshire Health and Human Sciences Ethics Committee (LMS/UG/UH/00397 and LMS/UG/UH02469) and at each of the five other universities. Approval had previously been obtained for collecting the historic dataset; the need for further approval for secondary analysis was explored but not required. 


\section{Results}

Reliable measurements were collected from 311 men and 231 women across the seven locations (Tables 2 and 3). There was evidence of a statistically significant relationship between measured height and ulna length in each of the ethnic groups except for Black Caribbean women which comprised only five participants $(P=0.059)$ (Table 4).

\section{Ulna - height relationships within groups}

In the White group, there were four Census 2011 subgroups but there were no participants in Irish or Traveller groups. The remaining two subgroups were combined in the first stage of model reduction (ethnicity was removed from the model) while the difference in the intercepts for males and females was retained. In the Asian group, Bangladeshi (Census $2011^{26}$ subgroup 11) and Chinese (subgroup 12) were combined with Other Asian background (subgroup 13) due to small number of participants ( 7 and 10 respectively). The first stage of model reduction suggested retaining ethnicity as a variable. Post-hoc Tukey test showed significant differences between Indian and Pakistani groups $(P=0.0004)$, and Indian and Other groups $(P=0.0008)$. The difference between Pakistani (subgroup 10) and Other Asian groups (subgroups 11-13) was not significant ( $P=0.979)$. Combining Pakistani with Other Asian groups resulted in a model which was not significantly different from the model with original three ethnic groups $(F=0.12, P=0.72)$. Combining the two remaining groups (removing ethnicity altogether) made the model significantly (although marginally) worse $(F=4.09, P=0.044)$. 
In the Black group, only African and Caribbean participants were present. For these two subgroups the model reduction exercise suggested keeping separate intercepts and slopes.

\section{Ulna - height relationships between groups}

As a result of the model reduction within groups, the final set of five subgroups comprised (A) White, (B) Indian, (C) Other Asian, (D) Black African and (E) Black Caribbean (Table 5). The first stage of model reduction suggested that there were no significant interactions (ANOVA, $F=0.89, P=0.57$ ) but both ethnicity and sex were significant (ethnicity $F=46.21, P<0.001$; sex $F=105.90, P<0.001$ ). This suggested a single slope and different intercepts for all five ethnic groups and sexes (Figure 3). This final model for the whole dataset was a reasonable fit $\left(R^{2}=0.77\right)$ with the residuals normally distributed $(\mathrm{W}=0.9974, \mathrm{P}=0.5924)$. The slope was 3.26 $(95 \% \mathrm{Cl} 2.96 \div 3.56)$ and the intercepts for these five groups are shown in Table 5 . Since the intercepts for Indian, other Asian and Black Caribbean subgroups were similar, an attempt was made to combine these, i.e. to give a final set of three comprising (F) White, (G) Indian, other Asian and Black Caribbean and $(\mathrm{H})$ Black African. A model with combined groups was significantly (although marginally) different from the model with five groups $(F=3.14, P=0.044)$ (Figure 4$)$. Residuals of this reduced model were normally distributed $(\mathrm{W}=0.997, \mathrm{P}=0.55)$ and the fit was similar $\left(R^{2}=0.77\right)$. The slope was $3.14(95 \% \mathrm{Cl} 2.85 \div 3.42)$ and the intercepts for the three groups are shown in Table 5. 
Comparison with historic dataset

The mean values for height predicted using the new equations derived in this study and those of Elia ${ }^{1}$ in the historic data set varied from measured height in most of the ethnic groups for men and women and with evidence of a statistical difference between measured and predicted values for Asian and Black participants (Table 6). In men, the 'best' predictions for height, i.e. smallest mean difference, which was not significantly different from the measured values, were observed in the Asian group using equation $\mathrm{C}$ (mean difference $[95 \% \mathrm{Cl}]:-0.6[-2.4,1.2] \mathrm{cm}, \mathrm{P}=0.486$ ), in the Black group using equation $\mathrm{G}(-0.4[-2.4,1.7] \mathrm{cm}, \mathrm{P}=0.721])$ and in the White group using equation $\mathrm{F}(+0.9[-1.4,3.2] \mathrm{cm}, \mathrm{P}=0.412)$. In women, the 'best' predictions for height were observed in the Asian group using equation $C(+0.5[-1.4,2.4] \mathrm{cm}$, $P=0.580)$, in the Black group using equation $G(-0.8[-2.8,1.2] \mathrm{cm}, P=0.412])$ and in the White group using the Elia equation for women aged $<65$ years $(+0.4[-1.4,2.2]$ $\mathrm{cm}, \mathrm{P}=0.675)$. 


\section{Discussion}

This multicentred study aimed to evaluate the relationship between ulna length and height in adults from a series of diverse ethnic groups and to consider whether ulna measurements can be used to provide useful predictions of height by proposing new prediction equations and testing them using a historic dataset. There was evidence of a statistically significant relationship between ulna length and height in the whole dataset collected and in all ethnic groups except Black Caribbean women where $\mathrm{P}=0.059$. This group comprised only five women, i.e. $<1 \%$ of participants and in some subsequent analyses their data were combined with others.

The new equations derived using the modelling process yielded better overall predictions of height at group level for non-White participants of the historic dataset than the predictions from the Elia ${ }^{1}$ equations which underpin the current recommendations in MUST screening ${ }^{31}$. This evaluation is based on the new equations having less mean bias between predicted and measured values for height and no evidence of statistically significant difference between predicted and measured values. The Elia equations were not derived for use in an ethnically diverse population but equations for predicting height from ulna length in adults from Asian and Black ethnic backgrounds have been published ${ }^{\mathrm{a}-\mathrm{e}}$. Most of these have used measurements methods that are not relevant to clinical practice, e.g. using post mortem bone length ${ }^{\mathrm{a}}$, or were derived only in older adults aged $\geq 65$ years ${ }^{16}$ or published $>50$ years ago and based on data from populations with different nutritional status and environmental exposure ${ }^{b, c}$. However, recent equations derived in Vietnam ${ }^{d}$ and West Bengale (women only) were tested with the historic data from Asian adults and the mean differences between measured height and values 
predicted using these equations were significantly greater than those determined using the new equations reported in this study (Appendix). The likely reason for this is that the UK datasets include people from a wider range of ethnicity than those in the Vietnam ${ }^{d}$ and West Bengal ${ }^{e}$ studies. The results indicate that the new equations may be more relevant for use in a diverse Asian population. No recent equations have been identified for using ulna length to predict height in Black African or Black Caribbean adults.

Clearly, no equations can provide accurate predictions for all individuals but the smaller mean difference between predicted and measured values indicate that errors arising from the new equations will be, on average, clinically less important than those previously reported in non-white participants ${ }^{25}$. It is important to note the difference in ethnic categories used for the data collected for the present study and those used for the historic dataset which comprised only crude categories of Asian, Black and White. This meant that there were options for testing the equations i.e. data from historic Asian participants could be used with new equations derived from Indian participants, other Asians or a combination of Indian, other Asians and Black Caribbean participants; in this case, all equations performed better than Elia equations and the best was equation $C$ that was derived from other Asians for both men and women. Similarly, data from historic Black participants could be used with Black African, Black Caribbean or a combination of Indian, other Asians and Black Caribbean participants; in this case, again, all equations performed better than Elia equations but, in this group, the best was equation $\mathrm{G}$ derived from combining data from Indian, other Asians and Black Caribbean participants for both men and women. In view of this, it seems reasonable to suggest that where no further details 
are known about a person's ethnicity, that equation $\mathrm{C}$ is best for Asian men and women and equation $\mathrm{G}$ for Black men and women. Where more specific details of ethnicity are known, alternatives are available but their accuracy and precision has not been tested in a second population using exactly the same ethnic groups. Equation $\mathrm{E}$ for women was derived using only five Black Caribbean women and is not recommended for use in practice. Equations $A$ and $F$, derived from White participants in the current study, did not perform better than the Elia equation for women so for consistency, are not recommended for use in practice. It is recognised that while combining some ethnic groups may be statistically appropriate, this may be challenging from a conceptual perspective so the presentation of all equations, i.e. for five groups and three groups, allows users flexibility.

The collection of data from several locations across England and Scotland enabled people from a range of ethnic backgrounds to participate. However, recruitment was opportunistic rather than systematic and some ethnic groups, i.e. mixed, multiple and other were not sufficiently represented to allow data to be considered. Allowing participants to self-identify their ethnic group is important but constrained by the options that are offered to them and is a sensitive area. A degree of categorisation is necessary to enable data to be analysed but the challenges associated with heterogeneous data and lack of clear boundaries is recognised ${ }^{32,33}$. This is exemplified by the modelling identifying the measurements of Indian participants of the current study as different from those of other Asian participants but heterogeneity of data was noted even within the Indian group. It is noted that for consistency, the England and Wales census categories for ethnic groups were used at all data 
collection sites, including in Scotland, although there are different categories used in Scotland ${ }^{34}$.

The statistically significant difference between left and right ulna length was surprising but asymmetry in long bone length on adults has been previously reported $^{35}$. Although the mean difference, $0.05 \mathrm{~cm}$, was small and clinically irrelevant, the $95 \%$ population variance between left and right ulna ranged from -1.11 to $+1.21 \mathrm{~cm}$ with $3.5 \%$ of all participants demonstrating a difference in left and right ulna length of between 1.5 and $2.5 \mathrm{~cm}$. Although recommendations based on data published by Elia ${ }^{1}$ advise that height should be predicted using left ulna length, the evidence from the current study indicates it would be better to measure ulna length on both arms and predict height from the mean of the two values.

This study is the first to collect and analyse data from a large number of adults from diverse ethnic groups in the UK in order to predict height from ulna length. Its methodological strengths include the range of geographical locations and intraobserver reliability of measurements. The limitations of the study include the opportunistic rather than the systematic recruitment of the participants and the lack of inter-site comparison of height and ulna measurements. However, robust attention to a single protocol and measurement training and observation were undertaken to try to minimise variation in procedures that might lead to substantial inter-observer error. The participants in the present study ranged in age from 21 to 82 years. Loss of height with aging is recognised ${ }^{36}$ but there is no evidence of comparable changes in ulna length and this is considered unlikely. As a result, combining participants across wide age ranges may also introduce errors. 
Height and long bone length are influenced by several factors in addition to ethnicity. These include intrauterine and childhood nutrition, socioeconomic factors and illness during periods of growth ${ }^{37-39}$. It was not possible to explore these factors in this study developing prediction equations from an adult population but they may confound resulting predictions. Social inequality is key driver of ethnic health inequalities ${ }^{40}$. In the UK, Pakistanis, Bangladeshis and Black ethnic minorities are overrepresented in the most deprived areas ${ }^{41}$ and there are marked ethnic differences in a range of health outcomes ${ }^{42-43}$. The disproportionate impact of social and material conditions on some ethnic groups, may lead to greater effects of socio-economic and other factors on height and long bone length in minority populations ${ }^{44}$. In order to address health inequalities and reduce health care inequity, appropriate resources are needed which are applicable to all sections of society. Such resources include the ability to accurately predict nutritional, body composition and other health indicators across ethnic groups ${ }^{45}$. This study aspires to make a contribution to this by providing new equations to predict height in adults who are not White.

In conclusion, this study has developed new equations from adults from diverse ethnic groups living in the community in the UK for predicting height from ulna length. Comparison of the new equations with a historic dataset shows that they are capable of providing mean predicted values of height that are closer to measured height than the MUST equations which are currently used in clinical practice. As a result, equations $\mathrm{C}$ are recommended for use in men and women of Asian ethnicity:

$$
\begin{array}{ll}
\text { men: } & \text { height }(\mathrm{cm})=3.26 \text { ulna }(\mathrm{cm})+83.6 \\
\text { women: } & \text { height }(\mathrm{cm})=3.26 \text { ulna }(\mathrm{cm})+77.6
\end{array}
$$


and equations $\mathrm{G}$ for men and women and women from Black ethnic groups:

men: $\quad$ height $(\mathrm{cm})=3.14$ ulna $(\mathrm{cm})+85.8$

women: $\quad$ height $(\mathrm{cm})=3.14$ ulna $(\mathrm{cm})+79.6$. 


\section{Acknowledgements}

The authors thank all participants, those who facilitated recruitment at all locations, the following who contributed to data collection and/or checking: Fareeha Anwar, Dahlia Bazano, Dilan Durmaz, Cleo Kamere, Mary Marufu, Beth Morgan, Evelyn Rendall and James Wimbury. They also thank Tatiana Tsikoura, who collected the historic dataset, and Professor David McCarthy who facilitated the opportunity to use this.

\section{Statement of authorship}

AMM contributed the original idea and led the collaboration, study design, analysis and writing of the manuscript.

AM led the overall data analysis.

FA provided critical review of the study design, data acquisition and interpretation.

$S G$ refined the study design and developed the data collection methodology.

MM contributed to the protocol development and data acquisition.

AC contributed to the acquisition and interpretation of data.

FD contributed to data analysis and checking.

$\mathrm{MH}$ contributed to the acquisition of data and its analysis and checking.

SL contributed to the acquisition and interpretation of data.

MJM contributed to the acquisition and interpretation of data and the manuscript discussion.

BP contributed to the acquisition and interpretation of data.

All authors contributed to the design of the study and / or the analysis of the data and / or to writing of the manuscript. All agreed the final version of the manuscript. 


\section{Conflict of interest statement}

All authors declare that they have no conflict of interests.

\section{Funding sources}

This research did not receive any specific grant from funding agencies in the public, commercial, or not-for-profit sectors. 


\section{References}

1 Elia, M. (2003) The 'MUST' Report. Nutritional Screening of Adults: A Multidisciplinary Responsibility. Development and Use of the 'Malnutrition Universal Screening Tool' ('MUST') for adults. Malnutrition Advisory Group (MAG), a Standing Committee of the British Association of Parenteral and Enteral Nutrition (BAPEN) Redditch: BAPEN.

2 Henry, C.J. (2005) Basal metabolic rate studies in humans: Measurement and development of equations. Public Health Nutr. 8:1133-52.

3 Pai, M.P. (2012) Drug dosing based on weight and body surface area: mathematical assumptions and limitations in obese adults. Pharmacotherapy 32:856-68.

4 Kirk, S.F.L., Hawke T., Sandford, S. et al. (2003) Are the measures used to calculate BMI accurate and valid for use in older people? J. Hum. Nutr. Diet. 16:366-67.

5 Cook, Z., Kirk, S., Lawrenson, S. et al. (2005) Use of BMI in the assessment of malnutrition in older subjects: reflecting on practice. Proc. Nutr. Soc. 64:313-7.

6 Hickson, M. \& Frost, G. (2003) A comparison of three methods for estimating height in the acutely ill elderly population. J. Hum. Nutr. Diet. 16:13-20.

7 Chumlea, W.C. \& Guo, S. (1992) Equations for predicting stature in white and black elderly individuals. J. Gerontol. 47:M197-M203.

8 Han, T.S. \& Lean, M.E. (1996) Lower leg length as an index of stature in adults. Int. J. Obes. Relat. Metab. Disord. 20:21-7.

9 Ritz, P. (2004) Validity of measuring knee-height as an estimate of height in diseased French elderly persons. J. Nutr. Health Ageing 8:386-8.

10 Brown, J.K., Whittemore, K.T. \& Knapp, T.R. (2000) Is arm span an accurate measure of height in young and middle-age adults ? Clin. Nurs. Res. 9:84-94.

11 Mohanty, S.P., Babu, S.S. \& Nair, N.S. (2001) The use of arm span as a predictor of height: A study of South Indian women. J. Orthop. Surg. 9:19-23. 
12 de Lucia E., Lemma, F., Tesfaye, F. et al. (2002) The use of armspan measurement to assess the nutritional status of adults in four Ethiopian ethnic groups. Eur. J. Clin. Nutr. 56:91-5.

13 Capderou, A., Berkani, M., Becquermin, M.H. et al. (2011) Reconsidering the arm spanheight relationship in patients referred spirometry. Eur. Respir. J. 37:157-63.

14 Bassey, E.J. (1986) Demi-span as a measure of skeletal size. Ann. Hum. Biol. 13:499502.

15 Hirani, V. \& Aresu, M. (2012) Development of new demi-span equations from a nationally representative sample of older people to estimate adult height. J. Am. Geriatr. Soc. 60:550-4.

16 Auyeung, T.W., Lee, J.S., Kwok, T. et al. (2009) Estimation of stature by measuring fibula and ulna bone length in 2443 older adults. J. Nutr. Health Aging 13:931-6.

17 Guerra, R.S., Fonseca, I., Pichel F. et al. (2014) Hand length as an alternative measurement of height. Eur. J. Clin. Nutr. 68:229-33.

18 Madden, A.M. \& Smith, S. (2014) Body composition and morphological assessment of nutritional status in adults - a narrative review: 1 Anthropometric variables. J. Hum. Nutr. Diet. 29:7-25.

19 Steele, M.F. \& Chenier, T.C. (1990) Arm-span, height, and age in black and white women. Ann. Hum. Biol. 17:533-41.

20 World Health Organization (1995) Physical status: The use and interpretation of anthropometry. Accessed February 24, 2019, at http://whqlibdoc.who.int/trs/WHO TRS 854.pdf

21 Launer, L.J. \& Harris, T. (1996) Weight, height and body mass index distributions in geographically and ethnically diverse samples of older persons. Age Ageing. 25:300-6. 
22 Reeves, S.L., Varakamin, C. \& Henry, C.J.K. (1996) The relationship between arm-span measurement and height with special reference to gender and ethnicity. Eur. J. Clin. Nutr. 50:398-400.

23 Chumlea, W.C., Guo, S.S., Wholihan, K. et al. (1998) Stature prediction equations for elderly non-Hispanic white, non-Hispanic black, and Mexican-American persons developed from NHANES III data. J. Am. Diet. Assoc. 98:137-42.

24 Cheng, J.C., Leung, S.S., Chiu, BS. et al. (1998) Can we predict body height form segmental bone length measurements? A study of 3,647 children. J. Pediatr. Orthop. 18:387-93.

25 Madden, A.M., Tsikoura, T. \& Stott, D.J. (2012) The estimation of body height from ulna length in healthy adults from different ethnic groups. J. Hum. Nutr. Diet. 25:121-8.

26 Office for National Statistics (2019) Ethnic group. Accessed February 24, 2019, at https://www.ons.gov.uk/methodology/classificationsandstandards/measuringequality/ethn icgroupnationalidentityandreligion\#ethnic-group

27 Office for National Statistics. (2006) Census 2001. A Guide to Comparing 1991 and 2001 Census Ethnic Group Data. Accessed January 27, 2011, at http://www.statistics.gov.uk/cci/article.asp?id=1471

28 Public Health England (2014) National Diet and Nutrition Survey: Results from years 1-4 (combined). Accessed February 24, 2019, at https://www.gov.uk/government/statistics/national-diet-and-nutrition-survey-results-fromyears-1-to-4-combined-of-the-rolling-programme-for-2008-and-2009-to-2011-and-2012 (see appendix L).

29 Crawley, M.J. (2005). Statistics: An introduction using R. Chichester: Wiley

30 R Core Team (2015). R: A language and environment for statistical computing. $R$ Foundation for Statistical Computing, Vienna, Austria. Accessed March 23, 2019 at https://www.R-project.org/ 
31 BAPEN (2016) Screening and 'MUST'. Accessed February 24, 2019, at https://www.bapen.org.uk/screening-and-must/must/

32 Aspinall, P.J. \& Chinouya, M. (2008) Is the standardised term 'Black African' useful in demographic and health research in the United Kingdom. Ethn. Health. 13:183-202.

33 Aspinall, P.J. (2011) The utility and validity for public health of ethnicity categorisation in the 1991, 2001 and 2011 British Censuses. Public Health 125:680-7.

34 Scottish Government (2008) Scotland's new ethnicity classification for Scottish official statistics and recommended for Scotland's 2011 census. Accessed February 24, 2019, at https://www.gov.scot/publications/scotlands-new-ethnicity-classification-scottish-officialstatistics-recommended-scotlands-2011-census/

35 Auerbach, B.M. \& Ruff, C.B. (2006) Limb bone bilateral asymmetry: variability and commonality among modern humans. J. Hum. Evol. 50:203-18.

36 van Leer, E.M., van Noord, P.A. \& Seidell, J.C. (1992) Components of adult height and height loss. Secular trends and effects of aging in women in the DOM project. Ann. Epidemiol. 2:611-5.

37 Gigante, D.P., Horta, B.L., Lima, R.C. et al. (2006) Early life factors are determinants of female height at age 19 years in a population-based birth cohort (Pelotas, Brazil). J. Nutr. 136:473-8.

38 Gigante, D.P., Nazmi, A., Lima, R.C. et al (2009) Epidemiology of early and late growth in height, leg and trunk length: findings from a birth cohort of Brazilian males. Eur. J. Clin. Nutr. 63:375-81.

39 Perkins, J.M., Subramanian, S.V., Davey-Smith, G. et al. (2016) Adult height, nutrition and population health. Nutr, Rev. 74:149-65.

40 Fiscella, K., Sanders, M.R. (2016) Racial and ethnic disparities in the quality of health care. Ann. Rev. Public Health 37:375-94. 
41 Cabinet Office (2017). Race disparity audit. Accessed March 23, 2019 at https://www.ethnicity-facts-figures.service.gov.uk/health

42 Balfour, P.C. Jr., Rodriguez, C.J. \& Ferdinand, K.C. (2015). The role of hypertension in race-ethnic disparities in cardiovascular disease. Curr. Cardio. Risk Rep. 9:18.

43 Tillin, T., Hughes, A.D, Godsland, I.F. et al., (2013). Insulin resistance and truncal obesity as important determinants of the greater incidence of diabetes in Indian Asians and African Caribbeans compared with Europeans: The Southall and Brent REvisited (SABRE) cohort. Diabetes Care 36:383-93.

44 Deurenberg, P. \& Deurenberg-Yap, M. (2003) Validity of body composition methods across ethnic population groups. Acta Diabetol. 40:Suppl.1;s246-9.

45 Heymsfield, S.B., Peterson, C.M., Thomas, D.M. et al. (2016) Why are there race / ethnic differences in adult body mass index-adiposity relationships? A quantitative review. Obes. Rev. 17:262-75.

a Trotter, M. \& Gleser, G.C. (1958) A re-evaluation of estimation of stature based on measurements of stature taken during life and of long bones after death. Am. J. Phys. Anthropol. 16:79-123.

b Allbrook, D. (1965) The estimation of stature in British and East African males. Based on tibial and ulnar bone lengths. J. Forensic Med.8:15-28.

c Joshi, N.B., Patel, M.P. \& Amin, M.G. (1965) Use of tibia and ulna in estimation of total body height. Indian J. Med. Res. 53:831-4.

d Bonell, A., Huyen, N.N., Phu, V.D. et al. (2017) Determining the predictive equation for height from ulnar length in the Vietnamese population. Asia Pac. J. Clin. Nutr. 26:982-6. e Mondal, M.K., Jana, T.K., Giri Jana, S. et al. (2012) Height prediction from ulnar length in females: a study in Burdwan district of West Bengal (regression analysis). J. Clin. Diagn. Res. 6:1401-4. 


\section{Table 1}

Summary of the participant groups in the present study and historic dataset and the equipment used to measure them

\begin{tabular}{|c|c|c|c|c|c|}
\hline Group & University & Recruitment location & Broad description of group & Stadiometer & Tape measure \\
\hline 1 & Liverpool Hope & Blackburn & $\begin{array}{l}\text { Indian and Pakistani Muslims } \\
\text { recruited from mosque }\end{array}$ & $\begin{array}{l}\text { Seca } 213 \\
\text { portable }\end{array}$ & Seca 201 \\
\hline 2 & Hertfordshire & London and Midlands & $\begin{array}{l}\text { Indian Sikhs recruited from two } \\
\text { temples }\end{array}$ & $\begin{array}{l}\text { Seca } 213 \\
\text { portable }\end{array}$ & Hoechstmass $^{b}$ \\
\hline 3 & Hertfordshire & South East England & $\begin{array}{l}\text { Black African and Black } \\
\text { Caribbean adults recruited from } \\
\text { churches }\end{array}$ & $\begin{array}{l}\text { Leicester height } \\
\text { measure }\end{array}$ & Seca 201 \\
\hline 4 & Plymouth & Plymouth & $\begin{array}{l}\text { Asians recruited from South Asian } \\
\text { society and university }\end{array}$ & $\begin{array}{l}\text { Seca } 213 \\
\text { portable }\end{array}$ & Idass $^{d}$ \\
\hline 5 & London Metropolitan & London & $\begin{array}{l}\text { Mixed group recruited from } \\
\text { university }\end{array}$ & $\begin{array}{l}\text { Leicester height } \\
\text { measure }\end{array}$ & Hoechstmass \\
\hline 6 & Leeds Beckett & Leeds & $\begin{array}{l}\text { Black Caribbean men recruited } \\
\text { from community hub }\end{array}$ & $\begin{array}{l}\text { Leicester height } \\
\text { measure }\end{array}$ & Harpendene \\
\hline 7 & Robert Gordon & Aberdeen & $\begin{array}{l}\text { Black African women recruited } \\
\text { from churches and university }\end{array}$ & $\begin{array}{l}\text { Leicester height } \\
\text { measure }\end{array}$ & Lufkin W606PM $^{\dagger}$ \\
\hline $\begin{array}{l}\text { Historic } \\
\text { dataset }\end{array}$ & London Metropolitan & London & $\begin{array}{l}\text { Mixed group recruited from } \\
\text { university }\end{array}$ & $\begin{array}{l}\text { Leicester height } \\
\text { measure }\end{array}$ & Butterflyg \\
\hline
\end{tabular}

aSeca, Birmingham, UK; bHoechstmass Balzer GmbH, Sulzbach, Germany; 'Marsden, Rotherham, UK; dIdass, Launceston, UK; eHarpenden, Holtain, Crymych, UK; ${ }^{\dagger}$ Apex Tool Group, Cleveland, USA; ${ }^{9}$ Butterfly, Shanghai, China. 


\section{Table 2}

Self-identified ethnicity of participants using England and Wales Census ${ }^{26} 2011$ categories

\begin{tabular}{|c|c|c|c|c|c|c|c|}
\hline & Ethnic category & Sub-group & Men & Women & Men & Women & Total \\
\hline 1 & \multirow[t]{4}{*}{ White } & English Melsh / Scottish / Northern Irish / British & 24 & 9 & \multirow[t]{4}{*}{38} & \multirow[t]{4}{*}{17} & \multirow[t]{4}{*}{55} \\
\hline 2 & & Irish & 0 & 0 & & & \\
\hline 3 & & Gypsy or Irish Traveller & 0 & 0 & & & \\
\hline 4 & & Any other White background ${ }^{a}$ & 14 & 8 & & & \\
\hline 5 & \multirow{4}{*}{$\begin{array}{l}\text { Mixed / multiple ethnic } \\
\text { groups }\end{array}$} & White and Black Caribbean & 2 & 4 & \multirow[t]{4}{*}{5} & \multirow[t]{4}{*}{9} & \multirow[t]{4}{*}{14} \\
\hline 6 & & White and Black African & 2 & 1 & & & \\
\hline 7 & & White and Asian & 0 & 0 & & & \\
\hline 8 & & Any other Mixed / Multiple ethnic background ${ }^{a}$ & 1 & 4 & & & \\
\hline 9 & \multirow[t]{5}{*}{ Asian / Asian British } & Indian & 110 & 133 & \multirow[t]{5}{*}{169} & \multirow[t]{5}{*}{160} & \multirow[t]{5}{*}{329} \\
\hline 10 & & Pakistani & 29 & 13 & & & \\
\hline 11 & & Bangladeshi & 7 & 0 & & & \\
\hline 12 & & Chinese & 7 & 3 & & & \\
\hline 13 & & Any other Asian background ${ }^{a}$ & 16 & 11 & & & \\
\hline 14 & \multirow{3}{*}{$\begin{array}{l}\text { Black / African / Caribbean } \\
\text { / Black British }\end{array}$} & African & 38 & 34 & \multirow[t]{3}{*}{97} & \multirow[t]{3}{*}{39} & \multirow[t]{3}{*}{136} \\
\hline 15 & & Caribbean & 59 & 5 & & & \\
\hline 16 & & Any other Black / African / Caribbean background ${ }^{a}$ & 0 & 0 & & & \\
\hline 17 & \multirow[t]{2}{*}{ Other ethnic group } & Arab & 1 & 3 & \multirow[t]{2}{*}{2} & \multirow[t]{2}{*}{6} & \multirow[t]{2}{*}{8} \\
\hline 18 & & Any other ethnic group ${ }^{a}$ & 1 & 3 & & & \\
\hline & & & & Total & 311 & 231 & 542 \\
\hline
\end{tabular}

a If selecting these categories, participants were invited to write a description of their ethnicity 


\section{Table 3}

Characteristics of the study participants by location of recruitment

\begin{tabular}{|c|c|c|c|c|c|c|c|c|c|}
\hline \multirow[t]{3}{*}{ Group } & \multirow{3}{*}{$\begin{array}{l}\text { Recruitment location } \\
\text { and participants }\end{array}$} & \multicolumn{4}{|c|}{ Men } & \multicolumn{4}{|c|}{ Women } \\
\hline & & \multirow{2}{*}{$n$} & \multicolumn{2}{|c|}{ Age (years) } & \multirow{2}{*}{$\begin{array}{c}\begin{array}{c}\text { Height } \\
(\mathrm{cm})\end{array} \\
\text { Mean } \pm \text { SD }\end{array}$} & \multirow[t]{2}{*}{$\mathrm{n}$} & \multicolumn{2}{|c|}{ Age (years) } & \multirow{2}{*}{$\begin{array}{c}\begin{array}{c}\text { Height } \\
(\mathrm{cm})\end{array} \\
\text { Mean } \pm \text { SD }\end{array}$} \\
\hline & & & Mean \pm SD & Range & & & Mean \pm SD & Range & \\
\hline 1 & $\begin{array}{l}\text { Blackburn: Indian } \\
\text { and Pakistani }\end{array}$ & 66 & $37.1 \pm 11.7$ & $21-65$ & $170.9 \pm 6.5$ & 60 & $39.5 \pm 12.4$ & $21-64$ & $155.7 \pm 5.8$ \\
\hline 2 & $\begin{array}{l}\text { London and } \\
\text { Midlands: Indian }\end{array}$ & 51 & $40.9 \pm 14.3$ & $22-78$ & $174.5 \pm 5.4$ & 69 & $45.1 \pm 14.9$ & $23-78$ & $160.2 \pm 4.4$ \\
\hline 3 & $\begin{array}{l}\text { South East England: } \\
\text { Black African \& } \\
\text { Black Caribbean }\end{array}$ & 17 & $39.8 \pm 12.2$ & $22-58$ & $173.0 \pm 7.2$ & 27 & $41.6 \pm 11.7$ & $26-68$ & $163.1 \pm 5.6$ \\
\hline 4 & $\begin{array}{l}\text { Plymouth: South } \\
\text { Asian }\end{array}$ & 37 & $31.7 \pm 13.3$ & $22-64$ & $172.8 \pm 6.3$ & 18 & $29.3 \pm 11.9$ & $22-65$ & $156.8 \pm 5.5$ \\
\hline 5 & $\begin{array}{l}\text { London: Mixed \& } \\
\text { Turkish }\end{array}$ & 69 & $29.5 \pm 9.9$ & $22-62$ & $175.8 \pm 6.9$ & 41 & $31.9 \pm 12.3$ & $22-66$ & $162.4 \pm 7.2$ \\
\hline 6 & $\begin{array}{l}\text { Leeds: Black } \\
\text { Caribbean }\end{array}$ & 71 & $44.2 \pm 17.1$ & $21-82$ & $176.8 \pm 7.4$ & 0 & - & - & - \\
\hline \multirow[t]{2}{*}{7} & $\begin{array}{l}\text { Aberdeen: West } \\
\text { African }\end{array}$ & 0 & - & - & - & 16 & $32.9 \pm 7.5$ & $22-46$ & $168.2 \pm 7.6$ \\
\hline & Total group & 311 & $37.3 \pm 14.5$ & $21-82$ & $174.3 \pm 6.9$ & 231 & $39.1 \pm 13.9$ & $21-79$ & $160.1 \pm 6.7$ \\
\hline \multicolumn{2}{|c|}{ Historic dataset: London } & 90 & $33.8 \pm 11.5$ & $21-62$ & $175.2 \pm 7.6$ & 90 & $31.2 \pm 9.3$ & $21-58$ & $162.3 \pm 6.7$ \\
\hline
\end{tabular}




\section{Table 4}

Characteristics of 520 study participants by ethnic groups for data included in modelling of new equations.

Data presented as mean \pm SD

\begin{tabular}{|c|c|c|c|c|c|c|c|c|c|c|}
\hline \multirow[t]{2}{*}{ Ethic group } & \multicolumn{5}{|c|}{ Men } & \multicolumn{5}{|c|}{ Women } \\
\hline & $n$ & $\begin{array}{c}\text { Age } \\
\text { (years) }\end{array}$ & $\begin{array}{c}\text { Measured } \\
\text { height } \\
(\mathrm{cm})\end{array}$ & $\begin{array}{c}\text { Ulna } \\
\text { length } \\
(\mathrm{cm})\end{array}$ & $\begin{array}{c}\mathrm{Ht} / \mathrm{U} \\
\text { relationship }\end{array}$ & $\mathrm{n}$ & $\begin{array}{c}\text { Age } \\
\text { (years) }\end{array}$ & $\begin{array}{c}\text { Measured } \\
\text { height } \\
(\mathrm{cm})\end{array}$ & $\begin{array}{c}\text { Ulna } \\
\text { length } \\
(\mathrm{cm})\end{array}$ & $\begin{array}{c}\mathrm{Ht} / \mathrm{U} \\
\text { relationship }\end{array}$ \\
\hline White & 38 & $30.8 \pm 11.0$ & $175.8 \pm 7.1$ & $27.1 \pm 1.2$ & $\begin{array}{c}\text { rho }=0.572 \\
P=0.000\end{array}$ & 17 & $29.3 \pm 8.7$ & $164.3 \pm 8.0$ & $25.1 \pm 1.1$ & $\begin{array}{c}\text { rho }=0.733 \\
P=0.001\end{array}$ \\
\hline Indian & 110 & $40.3 \pm 14.0$ & $173.1 \pm 6.2$ & $27.8 \pm 1.4$ & $\begin{array}{l}r=0.736 \\
P=0.000\end{array}$ & 133 & $42.6 \pm 14.4$ & $158.3 \pm 5.4$ & $25.2 \pm 1.3$ & $\begin{array}{l}r=0.688 \\
P=0.000\end{array}$ \\
\hline Other Asian & 59 & $29.5 \pm 8.6$ & $172.1 \pm 6.5$ & $27.2 \pm 1.3$ & $\begin{array}{l}r=0.645 \\
P=0.000\end{array}$ & 27 & $32.4 \pm 12.2$ & $157.6 \pm 6.6$ & $24.5 \pm 1.3$ & $\begin{array}{l}r=0.617 \\
P=0.001\end{array}$ \\
\hline Black African & 38 & $35.6 \pm 10.8$ & $176.4 \pm 6.6$ & $29.7 \pm 1.5$ & $\begin{array}{l}r=0.556 \\
P=0.000\end{array}$ & 34 & $38.6 \pm 11.6$ & $164.6 \pm 7.0$ & $28.0 \pm 1.4$ & $\begin{array}{l}r=0.647 \\
P=0.000\end{array}$ \\
\hline Black Caribbean & 59 & $45.8 \pm 17.9$ & $176.2 \pm 7.7$ & $29.0 \pm 1.5$ & $\begin{array}{l}r=0.766 \\
P=0.000\end{array}$ & 5 & $30.8 \pm 8.5$ & $166.9 \pm 9.4$ & $28.0 \pm 1.9$ & $\begin{array}{l}r=0.864 \\
P=0.059\end{array}$ \\
\hline $\begin{array}{l}\text { Indian, other Asian } \\
\text { \& Black Caribbean }\end{array}$ & 228 & $38.9 \pm 15.2$ & $173.6 \pm 6.8$ & $28.0 \pm 1.5$ & $\begin{array}{l}r=0.731 \\
P=0.000\end{array}$ & 165 & $40.6 \pm 14.5$ & $158.4 \pm 5.9$ & $25.1 \pm 1.4$ & $\begin{array}{l}r=0.703 \\
P=0.000\end{array}$ \\
\hline
\end{tabular}

Groups based on participants' self-identification and statistical grouping defined by modelling described in Results, Data analysis

$\mathrm{Ht} / \mathrm{U}$ : Association between measured height and ulna length examined using Pearson correlation except in White group where Spearman rank used as ulna length in men and measured height in women were not normally distributed. 


\section{Table 5}

New equations for predicting height from ulna length in adults based on (i) five and

(ii) three ethnic groups:

Predicted height $(\mathrm{cm})=($ ulna length $[\mathrm{cm}] \times$ slope $)+$ intercept .

Data presented as slope and intercepts (95\% confidence intervals)

\begin{tabular}{|l|l|l|l|}
\hline Equation & Groups & Male & Female \\
\hline \multicolumn{2}{|l|}{ (i) Slope $=3.26(2.96,3.56)$ and intercepts: } & $87.66(79.33,95.99)$ & $81.70(72.23,91.16)$ \\
\hline A & White & $82.30(72.55,92.04)$ & $76.33(65.45,87.22)$ \\
\hline B & Indian & $83.58(73.63,93.53)$ & $77.62(66.53,88.70)$ \\
\hline C & Other Asian & $79.49(69.27,89.70)$ & $73.52(62.18,84.87)$ \\
\hline D & Black African & $81.63(71.48,91.78)$ & $75.67(64.38,86.96)$ \\
\hline E & Black Caribbean & $90.92(83.13,98.72)$ & $84.67(75.76,93.59)$ \\
\hline (ii) Slope $=3.14$ (2.85, 3.42) and intercepts: & White & $85.80(76.63,94.96)$ & $79.55(69.27,89.83)$ \\
\hline F & Asian \& Black Caribbean & $83.09(73.42,92.75)$ & $76.84(66.06,87.61)$ \\
\hline G & Black African &
\end{tabular}

Example equation $\mathrm{E}$ for Black Caribbean men: Predicted height $=($ ulna length $\mathrm{x}$ $3.26)+81.63 \mathrm{~cm}$ 


\section{Table 6}

Comparison of predicted height in historic dataset of adults using new equations $\mathrm{A}-\mathrm{H}$ and Elia (2003)

\begin{tabular}{|c|c|c|c|c|c|c|c|c|c|c|c|}
\hline & & \multicolumn{10}{|c|}{ Height $(\mathrm{cm}):$ mean values \pm SD, difference [95\% confidence intervals] i.e. predicted - measured] } \\
\hline & $\mathrm{n}$ & Measured & $\begin{array}{l}\text { Predicted } \\
\text { A }\end{array}$ & $\begin{array}{l}\text { Predicted } \\
\text { B }\end{array}$ & $\begin{array}{l}\text { Predicted } \\
\text { C }\end{array}$ & $\begin{array}{l}\text { Predicted } \\
\text { D }\end{array}$ & $\begin{array}{l}\text { Predicted } \\
\text { E }\end{array}$ & $\begin{array}{l}\text { Predicted } \\
\text { F }\end{array}$ & $\begin{array}{l}\text { Predicted } \\
\text { G }\end{array}$ & $\begin{array}{l}\text { Predicted } \\
\mathrm{H}\end{array}$ & $\begin{array}{l}\text { Predicted } \\
\text { Elia (2003) }\end{array}$ \\
\hline \multicolumn{12}{|l|}{ Men } \\
\hline Asian & 30 & $170.9 \pm 5.2$ & - & $\begin{array}{l}169.0 \pm 3.2 \\
-1.9 \\
{[-3.7 ;-0.1]} \\
P=0.038\end{array}$ & $\begin{array}{l}170.3 \pm 3.2 \\
-0.6 \\
{[-2.4 ; 1.2]} \\
P=0.486\end{array}$ & - & - & - & $\begin{array}{l}169.3 \pm 3.1 \\
-1.6 \\
{[-3.4 ; 0.2]} \\
P=0.078\end{array}$ & - & $\begin{array}{l}175.0 \pm 3.5 \\
+4.1 \\
{[2.2 ; 5.9]} \\
P=0.000\end{array}$ \\
\hline Black & 30 & $178.4 \pm 7.6$ & - & & & $\begin{array}{l}175.3 \pm 5.0 \\
-3.1 \\
{[-5.2,-1.1]} \\
P=0.004\end{array}$ & $\begin{array}{l}177.4 \pm 5.0 \\
-1.0 \\
{[-3.0,1.0]} \\
P=0.000\end{array}$ & & $\begin{array}{l}178.0 \pm 4.8 \\
-0.4 \\
{[-2.4,1.7]} \\
P=0.721\end{array}$ & $\begin{array}{l}175.3 \pm 4.8 \\
-3.1 \\
{[-5.1,-1.0]} \\
P=0.004\end{array}$ & $\begin{array}{l}185.0 \pm 5.5 \\
+6.6 \\
{[4.5,8.6]} \\
P=0.000\end{array}$ \\
\hline White & 30 & $176.3 \pm 7.7$ & $\begin{array}{l}177.3 \pm 4.0 \\
+1.0 \\
{[-1.3 ; 3.3]} \\
P=0.392\end{array}$ & - & - & - & - & $\begin{array}{l}177.2 \pm 3.8 \\
+0.9 \\
{[-1.4 ; 3.2]} \\
P=0.412\end{array}$ & - & - & $\begin{array}{l}178.2 \pm 4.4 \\
+1.9 \\
{[-0.4 ; 4.1]} \\
P=0.105\end{array}$ \\
\hline \multicolumn{12}{|l|}{ Women } \\
\hline Asian & 30 & $157.7 \pm 4.7$ & - & $\begin{array}{l}156.9 \pm 2.4 \\
-0.8 \\
{[-2.7 ; 1.1]} \\
P=0.404\end{array}$ & $\begin{array}{l}158.2 \pm 2.4 \\
+0.51 \\
{[-1.4 ; 2.4]} \\
P=0.580\end{array}$ & - & - & - & $\begin{array}{l}157.1 \pm 2.3 \\
-0.52 \\
{[-2.4 ; 1.3]} \\
P=0.571\end{array}$ & - & $\begin{array}{l}164.0 \pm 2.1 \\
+6.4 \\
{[4.6 ; 8.2]} \\
P=0.000\end{array}$ \\
\hline Black & 30 & $165.7 \pm 6.4$ & & & & $\begin{array}{l}162.1 \pm 5.0 \\
-3.6 \\
{[-5.6,-1.6]} \\
P=0.001\end{array}$ & $\begin{array}{l}164.3 \pm 5.0 \\
-1.4 \\
{[-3.5,0.6]} \\
P=0.158\end{array}$ & & $\begin{array}{l}164.9 \pm 4.8 \\
-0.8 \\
{[-2.8,1.2]} \\
P=0.412\end{array}$ & $\begin{array}{l}162.2 \pm 4.8 \\
-3.5 \\
{[-5.5,-1.5]} \\
P=0.001\end{array}$ & $\begin{array}{l}170.9 \pm 4.3 \\
+5.2 \\
{[3.2,7.1]} \\
P=0.000\end{array}$ \\
\hline White & 30 & $163.5 \pm 6.2$ & $\begin{array}{l}162.1 \pm 4.1 \\
-1.4 \\
{[-3.2,0.3]} \\
P=0.109\end{array}$ & & & & & $\begin{array}{l}162.1 \pm 4.0 \\
-1.4 \\
{[-3.2,0.4]} \\
P=0.122\end{array}$ & & & $\begin{array}{l}163.9 \pm 3.5 \\
+0.4 \\
{[-1.4,2.2]} \\
\mathrm{P}=0.675\end{array}$ \\
\hline
\end{tabular}

Shaded cells identify 'best' prediction equation based on smallest mean difference between measured and predicted values and statistical difference between them greater than $P=0.05$. $P$ values: comparison of predicted and measured height using paired t test.

Equations A-E derived from five-group model: (A) White, (B) Indian, (C) Other Asian, (D) Black African and (E) Black Caribbean.

Equations F-H from three-group model: $(F)$ White, $(G)$ Indian, other Asian and Black Caribbean and $(H)$ Black African. 

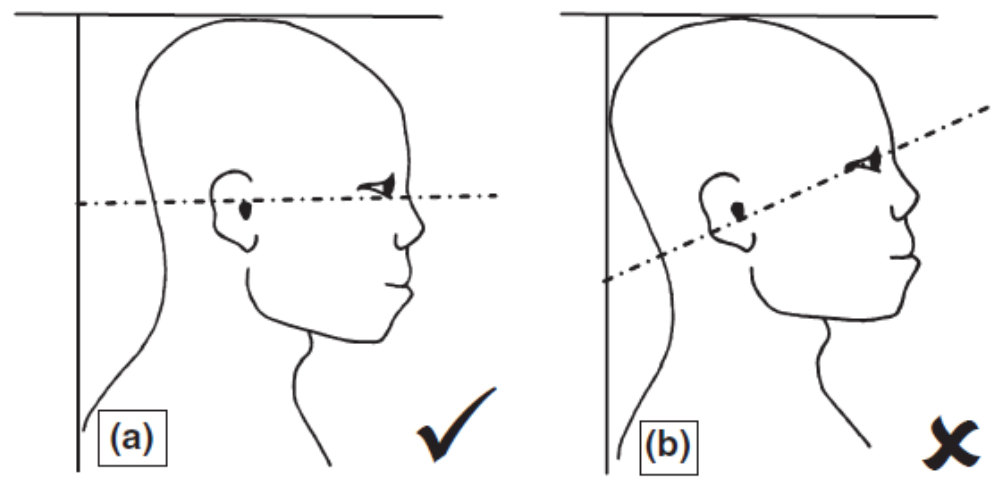

\section{Figure 1}

Position of head for measuring height using (a) the Frankfurt plane where lower eye socket is horizontally level with upper ear canal; (b) typical but incorrect position 


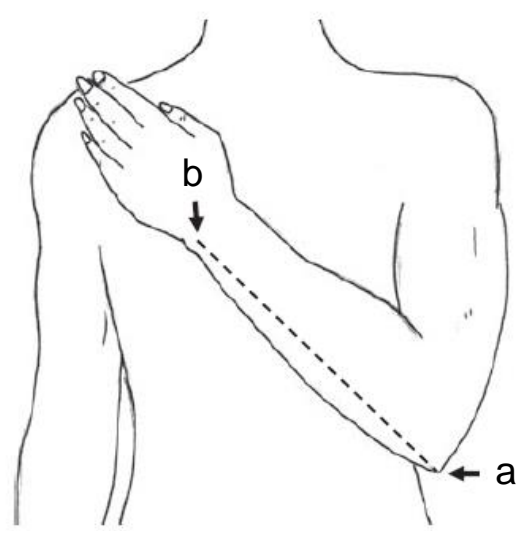

\section{Figure 2}

Position of arm for measuring ulna length between (a) olecranon process and (b) styloid process 
White, male

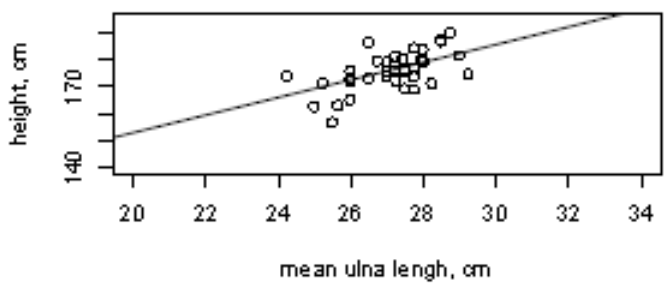

Indian, male

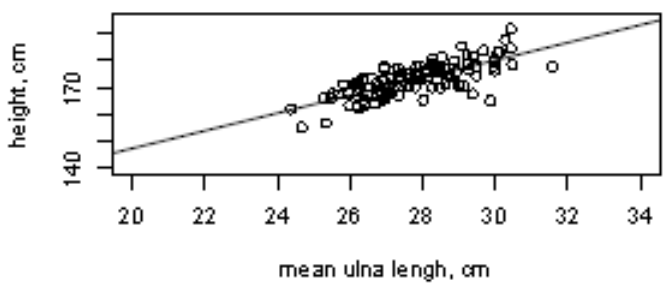

other Asian, male

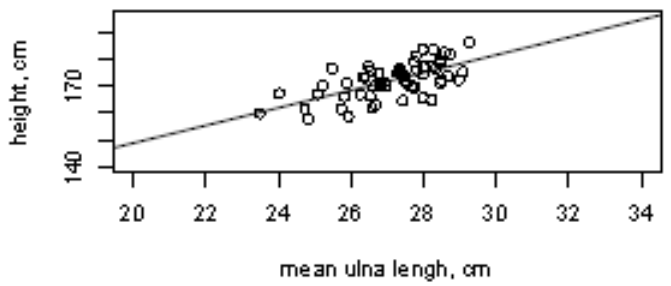

Black African, male

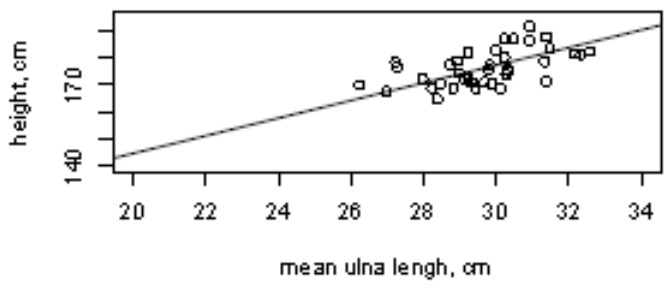

Black Caribbean, male

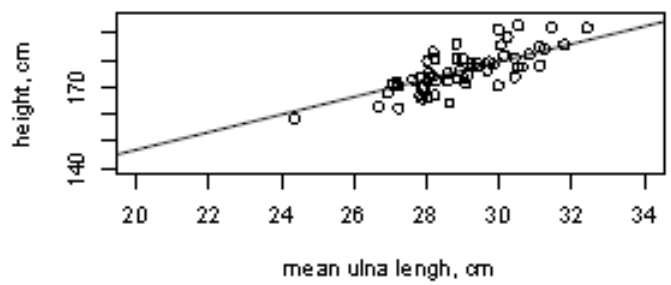

White, female

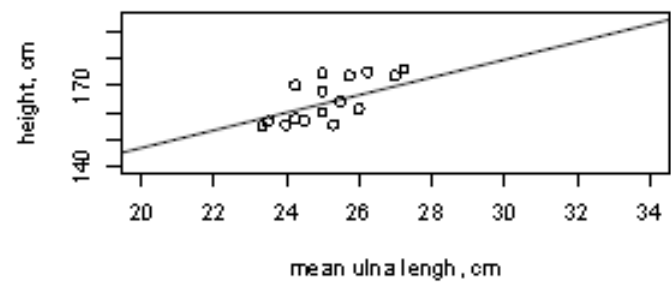

Indian, female

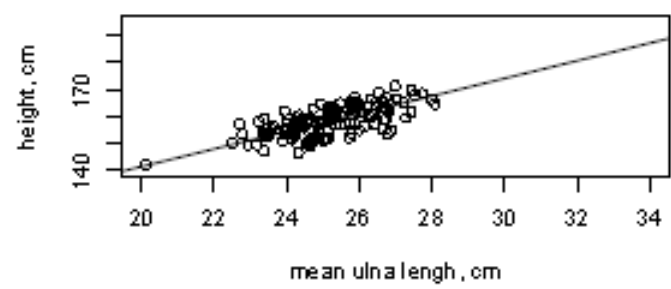

other Asian, female

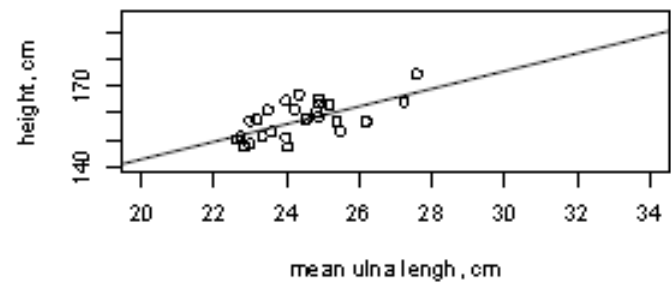

Black African, female

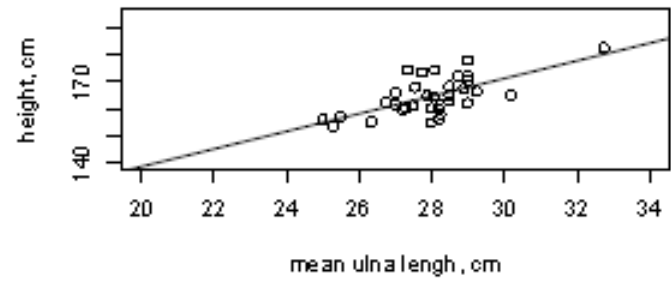

Black Caribbean, female

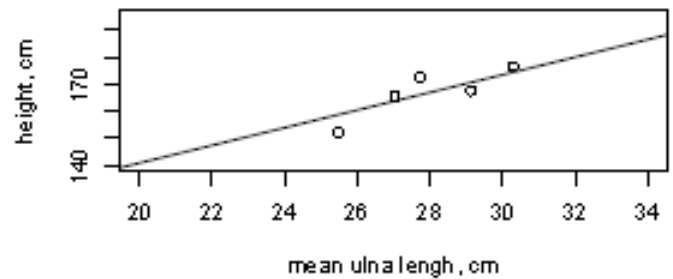

Figure 3

Relationship between height and ulna length with the fitted models for men and women in five groups: White, Indian, other Asian, Black African and Black Caribbean 
White, male

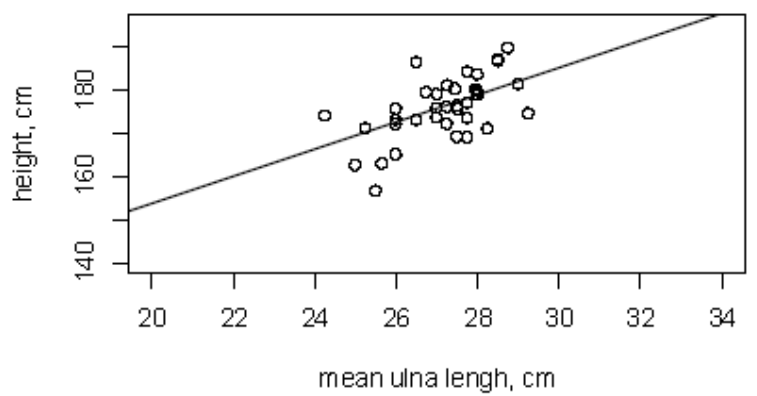

Asian + Black Caribbean, male

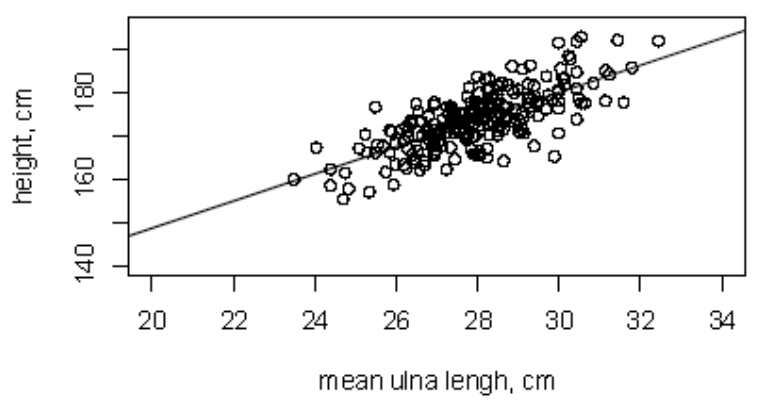

Black African, male

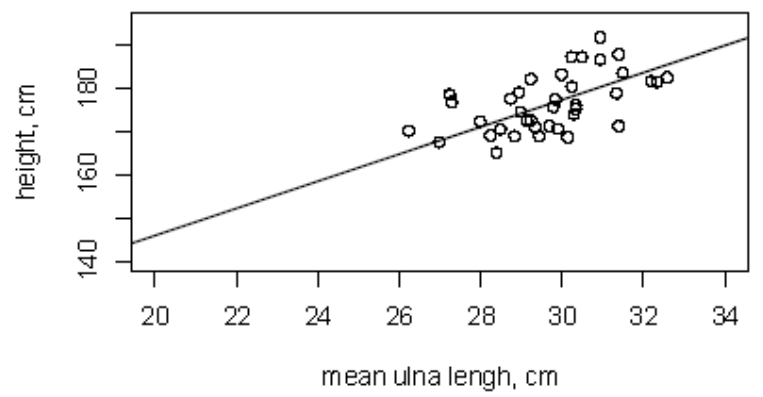

White, female

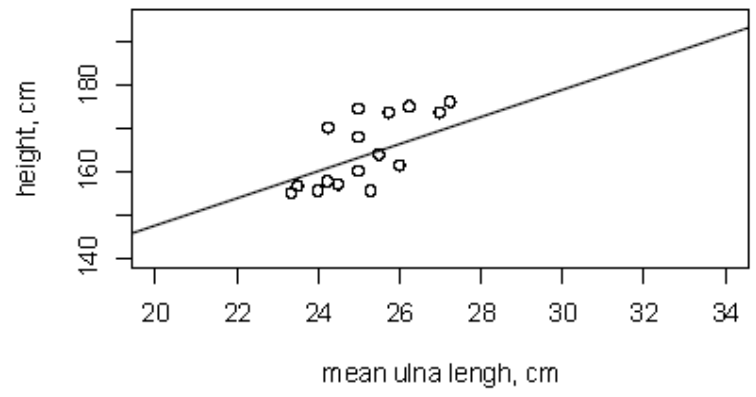

Asian + Black Caribbean, female

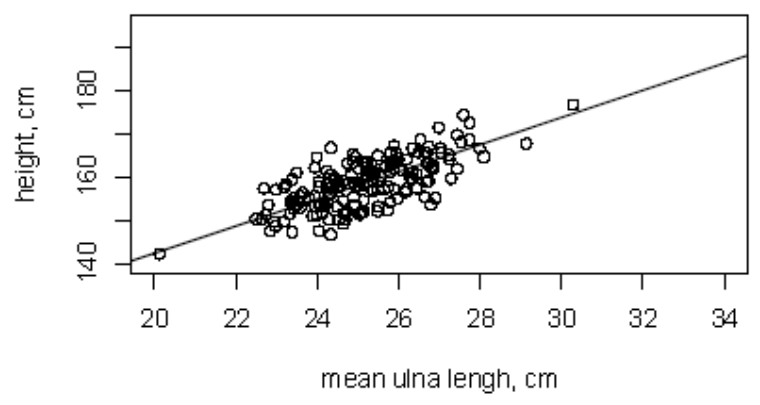

Black African, female

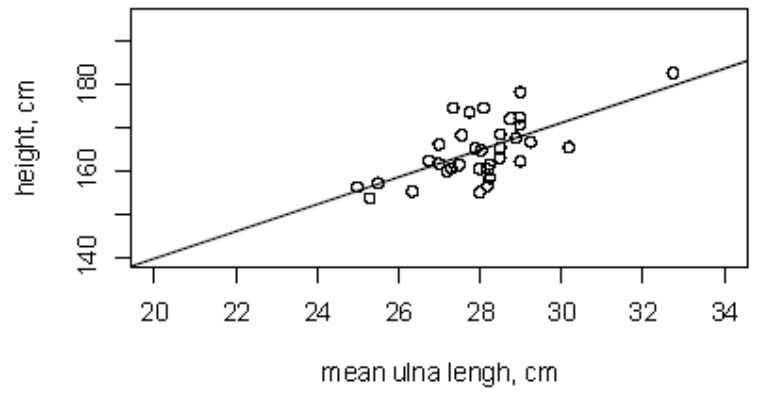

\section{Figure 4}

Relationship between height and ulna length with the fitted models for men and women in three groups: White, Asian \& Black Caribbean, and Black African 


\section{Appendix}

Additional text summarising the comparison of data from published equations

Equations for predicting height from ulna length for Vietnamese men and women by Bonell et al (2017) and for West Bengali women by Mondal et al (2012) were used to estimate height in 30 Asian men and 30 Asian women from the independent historic dataset (i.e. from Madden et al 2012).

Comparisons using paired $t$ tests were made between the Bonell and Mondal predictions and measured height and with predicted height calculated using equations $C$ i.e. the equations providing the best estimation for Asian participants in the current study.

Prediction equations used

\begin{tabular}{|l|l|l|}
\hline Bonell et al 2017 & Men & Height $(\mathrm{cm})=3.16$ ulna $(\mathrm{cm})+85.61$ \\
\hline Bonell et al 2017 & Women & Height $(\mathrm{cm})=2.97$ ulna $(\mathrm{cm})+85.80$ \\
\hline Mondal et al 2012 & Women & Height $(\mathrm{cm})=4.39$ ulna $(\mathrm{cm})+45.89$ \\
\hline Equation C & Men & Height $(\mathrm{cm})=3.26$ ulna $(\mathrm{cm})+83.58$ \\
\hline Equation C & Women & Height $(\mathrm{cm})=3.26$ ulna $(\mathrm{cm})+77.62$ \\
\hline
\end{tabular}

Measured and predicted values of height (mean \pm SD in $\mathrm{cm}$ )

\begin{tabular}{|l|l|l|}
\hline & Men $(\mathrm{n}=30)$ & Women $(\mathrm{n}=30)$ \\
\hline Measured height & $170.9 \pm 5.2$ & $157.7 \pm 4.7$ \\
\hline Predicted height Bonell & $169.7 \pm 3.1$ & $159.2 \pm 2.2$ \\
\hline \multicolumn{1}{|c|}{ difference: Bonell - measured } & $-1.2 \pm 4.8$ & $1.53 \pm 4.9$ \\
\hline Predicted height Mondal & - & $154.4 \pm 3.2$ \\
\hline difference: Mondal - measured & - & $-3.29 \pm 5.4$ \\
\hline Predicted height C & $170.3 \pm 3.2$ & $158.2 \pm 2.4$ \\
\hline \multicolumn{1}{|c|}{ difference: $C-$ measured } & $-0.6 \pm 4.8$ & $0.51 \pm 5.0$ \\
\hline
\end{tabular}

The mean difference between \{Bonell predicted - measured height\} and \{equation $\mathrm{C}$ predicted - measured height\} for men was $-0.6 \pm 0.1 \mathrm{~cm}, \mathrm{P}<0.00001$ and for women was $-1.01 \pm 0.2, P<0.00001$. The mean difference between \{Mondal predicted measured height\} and \{equation $C$ predicted - measured height\} for women was $3.81 \pm 0.8, P<0.00001$. 
This indicates that the equations $C$ proposed in the current study provided better predictions of measured height in this sample of Asian adults in the UK than those published for use in Vietnam or West Bengal.

Bonell, A., Huyen, N.N., Phu, V.D. et al. (2017) Determining the predictive equation for height from ulnar length in the Vietnamese population. Asia Pac. J. Clin. Nutr. 26:982-6.

Madden, A.M., Tsikoura, T. \& Stott, D.J. (2012) The estimation of body height from ulna length in healthy adults from different ethnic groups. J. Hum. Nutr. Diet. 25:121-8.

Mondal, M.K., Jana, T.K., Giri Jana, S. et al. (2012) Height prediction from ulnar length in females: a study in Burdwan district of West Bengal (regression analysis). J. Clin. Diagn. Res. 6:1401-4. 


\section{Supplementary Information}

Improved prediction equations for estimating height in adults from ethnically diverse backgrounds

\section{Best models for the relationship between ulna length and height within groups}

In all cases, the full model included ulna length (ulna), ethnic subgroups (ethnicity), sex, and all possible interactions $\left({ }^{*}\right)$ with the formula height $\sim$ ulna* ethnicity ${ }^{*}$ sex. Model reduction was done in $\mathrm{R}$ ( $\mathrm{R}$ Core Team, 2015). At the first stage of model reduction R's function step() was used to obtain the best model which, in most cases, removed the interactions from the models. Then the least different ethnic groups were combined in a step-by-step manner, and ANOVA procedure was used to test whether the model with combined groups was significantly worse than the model with all groups (See Supplementary information for details).

\section{White group}

In the White group, four Census 2011 subgroups were defined but there were no participants in Irish or Traveller groups leaving only two subgroups: English /Welsh / Scottish / Northern Irish / British and Any other White background. At the first stage, all the interactions and ethnicity were removed from the model with final model height $\sim$ ulna + sex not including any interactions. The final model was not significantly different from the full model (ANOVA, $F=0.25, P=0.94$ ).

\section{Asian group}

In the Asian group, Bangladeshi (Census 2011 subgroup 11) and Chinese (subgroup 12) were combined with Other Asian background (subgroup 13) due to small number of participants ( 7 and 10 respectively) leaving three groups: Indian, Pakistani and Other. At the first stage of model reduction all interactions were removed but ethnicity was retained height $\sim$ ulna + ethnicity (3 groups) $+\operatorname{sex}($ ANOVA, $F=0.82, P$ $=0.57$ ). Post-hoc Tukey test showed significant differences between Indian and Pakistani groups ( $P=0.0004)$, and Indian and Other groups $(P=0.0008)$. The difference between Pakistani and Other groups was not significant $(P=0.979)$. 
Combining Pakistani (subgroup 10) with Other group resulted in a model which was not significantly different from the model with original three ethnic groups (ANOVA, $F$ $=0.12, P=0.72$ ). Combining the two remaining groups (removing ethnicity altogether) made the model significantly (although marginally) worse ( $F=4.09, P=$ 0.044). Therefore, the final model was height $\sim$ ulna + ethnicity (2 groups) + sex.

\section{Black group}

In the Black group, only African and Caribbean participants were present. At the first stage, the three-way interaction and interaction between ulna and sex were removed but interaction between ulna and ethnic subgroups was retained with the final model height $\sim$ ulna + ethnicity + sex + ulna: ethnicity (ANOVA, $F=0.40, P=0.76)$. 


\section{Example code for Asian group}

The following variables need to be defined for the Asian group: height (measured height), ulna (ulna length), ethnicity (ethnic subgroup, including Indian, Pakistani and Other) and sex.

model.full $<-\operatorname{Im}$ (height $\sim$ ulna * ethnicity * sex)

step(model.full)

model. reduced $<-\operatorname{Im}($ height $\sim$ ulna + ethnicity + sex $)$

anova(model.full,model.reduced)

model.reduced.aov<-aov(height $\sim$ ulna + ethnicity + sex $)$

TukeyHSD(model.reduced.aov,"ethnicity")

levels(ethnicity) $[c(2,3)]<-" o t h e r "$

model.reduced $1<-\operatorname{Im}($ height $\sim$ ulna + ethnicity + sex $)$

anova(model.reduced,model.reduced1)

model.reduced2<- Im(height $\sim$ ulna + sex $)$

anova(model.reduced1, model.reduced2)

\# this suggests the final model without interactions

\# ethnicity has 3 categories

\# 'anova' is used for consistency, as it is used to compare

\# models with combined intercepts

\# needed for Tukey post hoc comparison

\# suggests no difference between Pakistani and Other

\# combining Pakistani with Other

\# ethnicity has 2 categories

\# no significant difference

\# model without ethnicity

\# significant difference 